\title{
OS SENTIMENTOS DE UMA SOCIEDADE REFLETIDOS EM MOVIMENTOS CINEMATOGRÁFICOS
}

\section{ARTIGO DE REVISÃO}

ROSA, Lucas Rafael Belém ${ }^{1}$

ROSA, Lucas Rafael Belém. Os sentimentos de uma sociedade refletidos em movimentos cinematográficos. Revista Científica Multidisciplinar Núcleo do Conhecimento. Ano 05, Ed. 11, Vol. 21, pp. 144-152. Novembro de 2020. ISSN: 24480959, Link de

acesso: https://www.nucleodoconhecimento.com.br/comunicacao/movimentoscinematograficos

\section{RESUMO}

Desde o expressionismo alemão, após o fim da primeira guerra, que tinha como base a visão da realidade como sendo um pesadelo coletivo, até o cinema novo, movimento brasileiro censurado pelo golpe militar na década de 60, o cinema viveu o seu ápice de criatividade genuína. Para a maioria das pessoas, essa é uma arte comunalmente vista como sendo um entretenimento, apenas. É claro, não é uma ideia completamente errônea. Entretanto, este artigo busca desmistificar, ou, talvez, mostrar, a possibilidade do cinema como sendo um excelente meio de comunicação, uma forma alternativa de narrar acontecimentos históricos. O objetivo, é que este artigo seja uma memória registrada sobre a importância do cinema em uma esfera social, um estudo que amplia a visão da sétima arte como uma arte além do círculo de cinéfilos. Ao todo, 4 movimentos marcantes na sétima arte foram escolhidos e dissertados, e seus principais filmes citados. Logo, vê-se que não só o cinema, mas a arte como um todo, é livre, viva e, consequentemente, adaptável. Livre para ser o que quiser ser e aberta a debates e discussões.

${ }^{1}$ Graduando em Jornalismo. 
Palavras-Chave: Movimentos Cinematográficos, Sétima Arte, História.

\section{INTRODUÇÃO}

A transição do cinema como uma arte em ascensão, negada por intelectuais no início do século XX, até uma arte estruturada, mas corrompida pela estimativa de lucro da indústria cultural, e que se aplica com facilidade no conceito de Theodor Adorno e Max Horkheimer, é, sem dúvida, curioso. Afinal, o cinema é uma arte que se desenvolveu em clubes e tinha como público principal grupos sociais desprivilegiados. Isso fez com que os filmes evoluíssem para algo dividido entre arte e indústria. Na maioria das vezes, são ambos. Além disso, foram várias as tentativas, por vezes uma resposta às condições socioeconômicas de um país em questão, de reerguer, ou reinventar o cinema como uma arte puramente genuína, ou, ao menos, em algo que se aproximasse disso. Um período de inspiração criativa, resultando em um movimento vanguardista ou pós-segunda guerra. Porém, isso não significa que cineastas tiveram total êxito em seus objetivos artísticos, principalmente cineastas vanguardistas.

A perda de sentido devido a uma narrativa linear e sem camadas é algo que afeta diretamente qualquer produção audiovisual. $\mathrm{O}$ cinema existe em base documental, podendo ela ser surrealista, realista, expressionista, ou, talvez, nada disso. E é nessa característica que surge a problemática de um herói que apazígua opiniões: nenhuma ideia é tão simples que não tenha divergências, isso transforma qualquer história em uma versão simplista da realidade, como visto em "Battleship Potemkin", 1926, de Serguei Eisenstein. Ou, infelizmente, como visto na maior parte do cinema de vanguarda, já que seu objetivo principal era chocar a burguesia.

Vamos ignorar, entretanto, o cinema vanguardista russo como propaganda política: revoluções não são dadas de forma fácil. Tendo o cinema uma base documentarista da realidade, uma manipulação continua sendo uma manipulação. Mas veja bem: a manipulação no cinema é intrínseca quando bem-intencionada e feita com o intuito de transmitir a mensagem desejada. 
“Intolerance: Love's Struggle Throughout the Ages", 1916, um filme de D. W. Griffith, chamado por muitos de pai do cinema. Um exemplo de manipulação malintencionada. A propaganda de uma autoimagem que surge após um ato não só de intolerância, mas criminoso e imoral. Filme feito por Griffith logo após o enorme sucesso entre a parcela branca e racista estadunidense de "The Birth of a Nation". Décadas de controvérsia, denunciado por Spike Lee em seu “BlacKkKlansman”, 2018.

E é então que chegamos no cerne do cinema como meio de comunicação: uma tragédia resultando em expressões artísticas e apontamentos políticos através da genialidade que só a arte proporciona. Fim de uma guerra mundial, levada a um único país através de um tratado desigual. Uma realidade com aparência de pesadelo, um sentimento pessimista sobre o futuro, o Expressionismo Alemão.

\section{DESENVOLVIMENTO}

O estouro da primeira guerra em 1914 fez com que produções cinematográficas europeias cessassem. Foram alguns anos até que a Alemanha, mesmo que completamente desestruturada, voltasse a criar arte. $O$ incentivo do governo alemão na criação de filmes foi intrínseco, curioso ao mesmo tempo. A questão, entretanto, não era produzir, e sim o que produzir. Países vencedores não queriam participar da venda e troca da arte alemã, assim como rejeitavam a possibilidade de exibir seus filmes em um país supostamente inimigo. Novamente, sobre o que falar? Talvez, transmitir os sentimentos de toda a sociedade fosse a melhor forma de criar cinema em tempos de caos. Na visão de Paul Leni, vemos um homem ridicularizado e deprimido por não conseguir parar de sorrir.

Os filmes expressionistas alemães foram os modificadores da visão preconceituosa que ricos e criticos de teatro da década de 20 tinham sobre o cinema, ao mesmo tempo em que cineastas americanos criavam a imagem, em uma época patriarcal extrema, do que chamam de "mulher melindrosa", que bebia, fumava e votava. "A Fool There Was”, 1915, dirigido por Frank Powell, a adaptação de um poema de mesmo nome, onde a "energia vampiresca" da feminilidade ameaçava o capitalismo do 
homem ariano em evolução. Uma produção estadunidense que, de acordo com Philip Kemp em seu livro "Tudo Sobre Cinema" (2011), contribuiu, inconscientemente, pro surgimento do genocídio nazista. E partimos, então, para 1940, exato 1 ano após o início da segunda guerra. A propaganda sarcástica e, surpreendentemente, falada, de Chaplin. Apesar da possibilidade de parecer uma afronta, um filme no qual aparentemente Hitler viu diversas vezes.

Por qual motivo o primeiro filme falado de Chaplin é talvez o seu mais politizado? Por qual motivo o cinema passa a ser arte durante o surgimento de obras em meio à fome e pobreza? A resposta é clara: o consenso sobre o que é arte só se torna universal após conseguir provar o seu valor quanto meio de comunicação, ao mesmo tempo em que incentiva a capacidade criativa de seus criadores. Entretanto, como observado por Marlene Fortuna em seu trabalho de nome "Arte: Um Meio de Comunicação e Educação No Aprimoramento da Personalidade" (1998): "A arte não é a representação fiel da realidade, mesmo a mais figurativa, ela é sempre uma mediação estética. Apresenta um ineditismo que a desvincula da superficialidade do real".

De 1940, voltemos agora alguns anos atrás. Ao caos político e a disputa ideológica nos Estados Unidos após o fim da primeira guerra. Não fale e não veicule, a liberdade da imprensa e de cineastas sendo assassinada pelo governo americano. "Scarface, A Vergonha de Uma Nação". Nem mesmo o título do filme escapou: a frase "A Vergonha de Uma Nação" foi acrescentada sem o apoio dos idealizadores do longa. Como se fosse culpa do cinema que Al Capone e Bonnie e Clyde fossem a capa de todos os jornais. Mas, de forma alguma isso significa que estúdios da época foram os mocinhos, na verdade, a produção desses filmes acontecia devido ao aparente interesse estadunidense pela violência. É curioso ver a tentativa de esconder, ou melhor, a negação em mostrar, por exemplo, os linchamentos frequentes de negros no país. Em "A História Brutal e Quase Esquecida da Era de Linchamentos de Negros nos EUA", Ángel Bermúdez cita o fundador da EJI, Bryan Stevenson: "Diga o nome de um afro-americano linchado entre 1877 e 1950? A maior parte das pessoas não conhece nenhum. Milhares de pessoas morreram, mas não se pode nomear uma sequer? Por quê? Porque não temos falado sobre isso". 
A Itália dos anos 40, por sua vez, estava mais preocupada em mostrar as dificuldades vividas pela classe trabalhadora. Com o fim da segunda guerra, o país vivia uma total desordem política e econômica. Entre os cineastas, era dominante a ideia de que se devia utilizar o mínimo de recursos possíveis: não havia locações, iluminação natural e atores não profissionais. Nomes como Roberto Rossellini e Vittorio De Sica começaram a chamar atenção, assim como seus filmes mais conhecidos: "Roma Città Aperta" e "Ladri Di Biciclette". O objetivo, como foi dito, era filmar as injustiças vividas pelas classes oprimidas. Era mais que cinema, era uma filosofia de vida. Ou, nas palavras de Katia Kreutz: "O Neorrealismo não era apenas um novo estilo cinematográfico, mas uma filosofia moral e ética para libertar o cinema do confinamento do sistema hollywoodiano de estúdios". Não foi apenas o cinema italiano, entretanto, que buscou denunciar o caos causado pela guerra iniciada na Alemanha. Edward Yang, por exemplo, levou às telas décadas depois o seu " $A$ Brighter Summer Day", filme que narra o surgimento de gangues criminosas na China após a grande guerra.

Já a invasão da guerra fria dentro das produções cinematográficas atingiu o seu ápice durante a década de 50. Uma possível instauração do comunismo era o atual terror do governo americano. Líderes temiam a influência do cinema sobre o povo. Dessa vez, não era o medo da população sonhar com uma vida de crime, e sim o medo de se alinharem ideologicamente com uma politica de esquerda. Afinal, a ideia de que algo pudesse colocar em risco o capitalismo do homem ariano em evolução estava mais atual do que nunca. Mas sem o homem ariano. E, dessa vez, sendo o comunismo o real vilão. Hollywood estava cercada por todos os lados, com cineastas sendo cassados e denunciados. Investigações curtas, mas o suficiente pra acabar com a era de ouro do cinema em Hollywood. Esse caos, juntamente das mortes de importantes influências, como Marilyn Monroe, deu início a uma nova fase no cinema americano: a Nova Hollywood.

A Nova Hollywood tinha uma visão quase tão pessimista sobre a realidade quanto o Expressionismo Alemão, claro, em um nível de impacto muito menor. A ida do homem à lua e o avanço da tecnologia, como a recente invenção da televisão, tornou o futuro 
quase que completamente impossível de ser lido. Havia os que pensavam no futuro sendo algo diretamente relacionado ao fim da humanidade, outros acreditavam no total controle de governantes sobre a população. Independente da crença, cineastas criaram um amor incondicional por finais-twists, que eram tão inesperados quanto o próprio futuro. Uma mulher que aceita o filho recém-nascido, cujo pai é algo maligno. Ou, então, cientistas que viajam para o futuro e encontram lá o fim da humanidade, mas a ascensão de uma civilização de macacos.

Se o dilema do cinema americano era a imprevisibilidade do futuro, o cinema nacional brasileiro, entretanto, se preocupava com o presente. $O$ golpe militar quase se assemelhava às perseguições ideológicas em Hollywood anos antes. A denúncia censurada em "Cabra Marcado Para Morrer", tido por muitos como o melhor documentário nacional, é um triste relato sobre a fragilidade da liberdade de expressão. Uma onda de criatividade iniciada no início da década de 60 , o movimento conhecido como Cinema Novo sendo interrompido de forma brusca pela antidemocracia. Entretanto, falamos de uma época em que o cinema nacional estava sendo amplamente reconhecido em importantes festivais ao redor do mundo. "Vidas Secas", indicado à Palma de Ouro no festival de Cannes, por exemplo. Era óbvio que havia uma obrigação dos militares em não censurar por completo o cinema brasileiro, mas, ainda assim, com censura. Poucos anos após o golpe militar, cineastas, de boca fechada e mãos atadas, se sentiam na obrigatoriedade de criar denúncias de maneira sútil. O próprio título dos filmes feitos durante e pós o golpe entregavam o absurdo que acontecia no Brasil: "Matou a Família e foi ao Cinema".

Alguns nomes, como Steven Spielberg, até então, deram fim a esse surgimento de movimentos revolucionários. A década de 80 foi dominada pela cultura pop, desde a segunda invasão musical britânica até os filmes trash de baixo orçamento. Um mundo longe da perfeição, mas um momento em que cineastas puderam finalmente respirar. No Brasil, o golpe militar estava perto de decretar o seu fim após tantos estragos. Entretanto, o cinema nacional brasileiro continuou traçando o rumo de um cinema politizado. Desde "O Ano em que Meus Pais Saíram de Férias”, lançado em 2006 e 
que resgata a memória da dura época de censura, até o recente "Bacurau", que ganhou notoriedade internacional tal como "Vidas Secas" em sua época de estreia.

Como foi dito, um mundo longe da perfeição, e, sendo assim, não foram apenas os cineastas brasileiros que continuaram produzindo filmes de resistência. Em um cenário global, um diretor da Espanha chamava atenção: Pedro Almodóvar. Em seu filme de estreia, vemos uma mulher casada indo de encontro à um relacionamento lésbico, pois seu marido não a satisfaz. Essa era e é uma entre as várias questões postas em debate não só no cinema, mas na arte como um todo: os direitos da comunidade LGBT, ou, como era chamado na época, LGB. "Paris Is Burning", 1990, documentário dirigido por Jennie Livingston e que narra o cotidiano de gays e transexuais na Nova York de 1980: "eu sou o que sou, sou minha própria criação especial". Foram décadas de luta por direitos básicos. O documentário de Jennie Livingston nunca esteve tão atual: em 2019, veio à tona a lei de criminalização da homofobia no Brasil.

Temos, então, a perspectiva do Almodóvar através de uma militância justa, que não só diz respeito aos LGBT's. Um diretor que cresceu tendo de base a figura feminina como um exemplo de força. O protagonismo feminino nos filmes do Almodóvar está sempre diretamente relacionado à luta por direitos iguais. Um diretor progressista, com filmes progressistas. Tal como as ideias revolucionárias dos movimentos cinematográficos citados.

\section{CONCLUSÃO}

Não é uma obrigatoriedade que a sétima arte assuma uma postura de arte politizada. A arte é livre, assim como Sebastião Salgado fotografa injustiças, Monet pintava paisagens. Certamente, entretanto, isso não impediu que o cinema, em diferentes momentos da história, assumisse uma postura de porta-voz da sociedade, denunciando injustiças e transmitindo emoções mútuas.

É impossível prever se haverá outro momento em que cineastas serão tomados por uma vontade incontrolável de criar. Talvez, as denúncias do mundo moderno não mais 
necessitem de uma onda de filmes criticos, o que não significa que eles não devam ser feitos, não significa, também, que o cinema deixou de ser um meio de resistência. Afinal, o movimento Black Lives Matter, por exemplo, faz com que tanto "BlacKkKlansman" (2018), quanto “To Kill a Mockingbird” (1962), sejam extremamente atuais.

\section{REFERÊNCIAS}

A BRIGHTER SUMMER DAY. Direção: Edward Yang. Produção de Yu Wei-yen. Local: Taiwan. Yang \& His Gang Filmmakers, 1991.

A FOOL THERE WAS. Direção: Frank Powell. Produção de William Fox. Local: Estados Unidos. Box Office Attractions Company, 1915.

BACURAU. Direção: Kleber Mendonça Filho. Produção de Emilie Lesclaux. Local: Brasil. SBS Productions, 2019.

BATTLESHIP POTEMKIN. Direção: Serguei Eisenstein. Produção de Jacob Bliokh. Local: Rússia. Mosfilm, 1925.

BERMÚDEZ, Ángel. A História Brutal e Quase Esquecida da Era de Linchamentos de Negros nos EUA. BBC Mundo, 2018. Disponível em: bbc.com/portuguese/internacional-43915363. Acesso em: 24 de setembro de 2020.

BLACKKKLANSMAN. Direção: Spike Lee. Produção de Jason Blum. Local: Estados Unidos. Universal Studios, 2018.

BONNIE AND CLYDE. Direção: Arthur Penn. Produção de Warren Beatty. Local: Estados Unidos. Warner Bros.-Seven Arts, 1967.

CABRA MARCADO PARA MORRER. Direção: Eduardo Coutinho. Produção de Eduardo Coutinho. Local: Brasil. Gaumont do Brasil, 1984. 
CINEMA NA DITADURA. Memórias da Ditadura. Disponível em: memoriasdaditadura.org.br/cinema. Acesso em: 24 de setembro de 2020.

FORTUNA, Marlene. Arte: Um Meio de Comunicação e Educação No Aprimoramento da Personalidade. Revista LÍBERO, 1998. Disponível em: http://www.portcom.intercom.org.br/pdfs/097ef92e6dd2c4858e9d24e2640e5872.pdf. Acesso em: 24 de setembro de 2020.

INTOLERANCE: LOVE'S STRUGGLE THROUGHOUT THE AGES. Direção: D. W. Griffith. Produção de D. W. Griffith. Local: Estados Unidos. Triangle Distributing Corporation, 1916.

KEMP, Philip. Tudo Sobre Cinema. Rio de Janeiro: Sextante, 2011, 576 páginas.

KREUTZ, Katia. Neorrealismo Italiano. Academia Internacional de Cinema, 2018. Disponível em: aicinema.com.br/neorrealismo-italiano. Acesso em: 24 de setembro de 2020.

LADRI DI BICICLETTE. Direção: Vittorio De Sica. Produção de Ercole Graziadei. Local: Itália. Produzioni De Sica, 1948.

MATOU A FAMÍLIA E FOI AO CINEMA. Direção: Júlio Bressane. Produção de Júlio Bressane. Local: Brasil. Embrafilme, 1969.

O ANO EM QUE MEUS PAIS SAÍRAM DE FÉRIAS. Direção: Cao Hamburger. Produção de Cao Hamburger. Local: Brasil. Gullane Filmes, 2006.

PARIS IS BURNING. Direção: Jennie Livingston. Produção de Jennie Livingston. Local: Estados Unidos. Academy Entertainment Off White Productions, 1990.

PEPI, LUCI Y BOM. Direção: Pedro Almodóvar. Produção de Pepón Coromina. Local: Espanha. Fígaro Films, 1980. 
PEREIRA, Maria Eduarda; NEVES, Helen. Criminalização da LGBTfobia: Uma Problematização Necessária. Revista Âmbito Jurídico, 2019. Disponível em: https://ambitojuridico.com.br/cadernos/direito-constitucional/criminalizacao-daIgbtfobia-uma-problematizacao-necessaria/\#_ftn2. Acesso em: 24 de setembro de 2020.

PLANET OF THE APES. Direção: Franklin J. Schaffner. Produção de Arthur P. Jacobs. Local: Estados Unidos. APJAC Productions, 1968.

ROMA CITTÀ APERTA. Direção: Roberto Rossellini. Produção de Giuseppe Amato. Local: Itália. Minerva Film, 1945.

ROSEMARY'S BABY. Direção: Roman Polanski. Produção de William Castle. Local: Estados Unidos. William Castle Enterprises, 1968.

SCARFACE. Direção: Howard Hawks. Produção de Howard Hughes. Local: Estados Unidos. The Caddo Company, 1932.

THE BIRTH OF A NATION. Direção: D. W. Griffith. Produção de D. W. Griffith. Local: Estados Unidos. David W. Griffith Corp, 1915.

THE GREAT DICTATOR. Direção: Charlie Chaplin. Produção de Charlie Chaplin. Local: Estados Unidos. Charles Chaplin Film Corporation, 1940.

THE MAN WHO LAUGHS. Direção: Paul Leni. Produção de Paul Kohner. Local: Estados Unidos. Universal Studios, 1928.

TO KILL A MOCKINGBIRD. Direção: Robert Mulligan. Produção de Alan J. Pakula. Local: Estados Unidos. Universal International Pictures, 1962.

VIDAS SECAS. Direção: Nelson Pereira dos Santos. Produção de Luiz Carlos Barreto. Local: Brasil. Produções Cinematográficas Herbert Richers, 1963.

Enviado: Outubro, 2020. 
Aprovado: Novembro, 2020.

Disponível em: https://www.nucleodoconhecimento.com.br/comunicacao/movimentoscinematograficos 